\title{
Breve relato sobre a
}

\section{expansão da coleta e \\ tratamento de esgotos- \\ São Paulo, Brasil (1900-2000)}

\author{
Vanessa Meloni Massara* \\ Vanessa.massara@gmail.com
}

\begin{abstract}
Resumo
Visando a contribuir na recuperação da história do saneamento no Brasil e para o detalhamento da análise quanto à existência das redes, este artigo pretende fornecer uma visão geral sobre a implantação e expansão da infraestrutura de esgotos na cidade de São Paulo, durante o século XX (1900-2000). A análise de sua evolução físico-temporal, por meio da história ao longo do século XX seguiu o desenvolvimento urbano com dados numéricos e mapas, apresentam em um período de 100 anos como a coleta de esgoto evoluiu nos distritos paulistanos. Ao final, faz-se uma breve analogia com os fatores técnicos sociais, políticos e urbanísticos que contribuiram para a priorização na escolha das áreas de expansão da infraestrutura através da cidade. Como conclusão constata-se que a instalação dos serviços começou na área central da cidade, estendendo - se de forma aproximadamente concêntrica ao redor desse primeiro centro, abrangendo a região atualmente denominada centro expandido. Após a década de 70, a implantação vai se consolidando na região periférica da cidade, principalmente nas zonas sul e leste, as menos atendidas até então até o ano 2000, quando a cobertura do serviço era considerada em termo de $91 \%$.
\end{abstract}

\section{Palavras-chave}

Saneamento; desenvolvimento urbano; cidade de São Paulo

\section{Brief report about the expansion of sew-age colection and treatment-São Paulo, Brazil (1900-2000)}

\begin{abstract}
Aiming to contribute to the recovery of the sanitation history in Brazil and with to the analysis of the existence of the networks, this article intends to provide an overview about the implantation and expansion of the sewage infrastructure in the city of São Paulo during the 20th century (1900-2000). The analysis of its physical and temporal evolution is made through the history research during the 20th century, followed associated to the urban development using numerical data and maps, presenting in a period of 100 years as the collection of sewage has evolved in the districts of São Paulo. At the end, a brief analogy is made considering technical, social, political and urban factors that contributed to the prioritization in the choice of the expansion areas for the infrastructure through the city. In conclusion was verified that, the installation of services, began in the central area of the city, extending - is roughly concentrically around this first center - covering the region now called "expanded center". After the 70's, the service is consolidated in the peripheral region of the city, mainly in the southern and eastern areas under-served until 2000, when the service coverage was considered around $91 \%$.
\end{abstract}

\section{Keywords}

Sanitation; urban development; São Paulo

\footnotetext{
*Doutora do em Energia (IEE/USP) e pós-doutorado em Engenharia de Produção (POLI/USP). Pesquisadora colaboradora da USP e Engenheira Civil especialista em método não destrutivo (trenchless technology).
} 


\section{Introdução}

Considerando o enfoque histórico sobre sua expansão, os trabalhos da Agência Nacional das Águas (2007), de Motta (1911), Novaes (1927), Rolnik (1997), catálogos e mapas da SABESP (1976; 1995; 1998; 2002) e D.A.E.E. (1970), Telles (1984, Vol.2) e os artigos da Revista D.A.E. (1936 - 1995), sobre os planos para a evolução do abastecimento de água representados pelos artigos de Azevedo Netto et al (1984); Queiroz (1964); Santiago (1964); Whitaker (1943; 1946) e Yassuda (1976) e os Censos do IBGE (1970; 1991) forneceram material importante para caracterizar o incremento da rede e os déficits dos sistemas.

O relatório da Associação Nacional dos Geógrafos, organizado por Azevedo (1958, 4 vol.), apresenta várias informações tanto sobre infraestrutura como sobre o perfil socioeconômico da população do início do século a década de 50. O PUB - Plano Urbanístico Básico (PMSP, 1968), através dos volumes 2: Serviços Urbanos e 5: Infraestrutura traça o perfil das redes através de mapas e dados quantitativos que foram combinados às informações sobre as questões de expansão da cidade.

Os relatórios da Prefeitura de 1961 e 1985 descrevem a condição das redes e possibilitaram a montagem dos primeiros mapas "rua a rua". Os Sumários de Dados (1977/1998) e livro sobre a memória estatística de São Paulo (1993), ambos produzidos pela EMPLASA, fornecem dados que, após serem reunidos, foram compilados em tabelas que ajudam na caracterização da expansão dos serviços a partir da década de 70 .

Trabalhos da Secretaria Municipal de Planejamento - SEMPLA: Diagnóstico regionalizado do $\mathrm{Mu}-$ nicípio de São Paulo (1983), e a coletânea sobre o perfil socioeconômico da cidade (2000) detalham a situação por região da cidade. Também o Plano do Município de
São Paulo 1985/2000 (1985), da Coordenadoria Geral de Planejamento- COGEP (1975, 16vol.) e da Companhia de Processamento de Dados - PRODAM (2001/ 2006) colaboraram com dados para a década de 80 , fornecendo tabelas com a evolução do tratamento de esgotos e informações detalhadas sobre o salto na implantação desse serviço, verificado na primeira metade da década de 80. Por fim, a dissertação de Massara (2002), auxiliando em especial na confecção de mapas sobre a distribuição territorial da rede.

A escolha da cidade de São Paulo foi baseada na complexidade do município paulistano, fonte inesgotável de debates e conclusões sociais, econômicas e técnicas para expansão de infraestruturas.

Como limitação espacial dentro da Cidade de São Paulo, usaremos a divisão em 96 distritos em conformidade com as informações disponibilizadas pela Secretaria Municipal de Planejamento Urbano (SEMPLA, 2000).

\section{Cronologia administrativa do serviço de coleta de esgotos na cidade de São Paulo, Brasil}

Em 1863, por meio de contrato entre o Governo da Província e a concessionária representada pelo coronel Antonio Proost Rodovalho, o major Benedicto Antônio da Silva e Daniel Makinson Fox, foi formada a Companhia Cantareira de Águas e Esgoto. Em 1877, a mesma concessionária solicitou um contrato para concessão de "um sistema completo de esgotos e despejos dos prédios desta capital” (MOTTA, 1911, p. 36).

Até 1892, os serviços foram prestados por essa Companhia, quando o Governo do Estado decidiu rescindir o contrato celebrado pela impossibilidade, confessada pela própria Companhia, de cumprir o acordado. 
Assim, por decreto de janeiro de 1893, foi criada a Repartição de Águas e Esgotos da Capital.

Em 1905 (com modificações em 1926), depois da crise no abastecimento de água, foi instituída a comissão das Obras de Saneamento da Capital, a qual caberia, entre outras determinações, um estudo para o Plano Geral da rede de águas pluviais e esgotos. Na década de 30, foi elaborado um "plano de emergência" visando a regularizar e expandir o abastecimento de água da $\mathrm{Ca}$ pital (NOVAES, 1927).

Até 1954, o panorama administrativo se manteve o mesmo. Nesse ano, foi criado o DAE (Departamento de Águas e Esgotos), que tinha sob seu comando, além da Capital, os municípios vizinhos do ABC e Guarulhos, sendo submetido à Secretaria de Viação e Obras Públicas (AZEVEDO NETTO, 1984).

No início dos anos 60 , foi aprovado um plano criando seis sistemas para coleta e tratamento de esgotos, que incluíam os municípios vizinhos do $\mathrm{ABC}$, Guarulhos, Mauá e Osasco. Em 1968 e 1970, respectivamen- te, foram criadas a Comasp (Companhia Metropolitana de Água de São Paulo), a Sanesp (Companhia Metropolitana de Saneamento de São Paulo) e o Fesb (Fomento Estadual de Saneamento Básico) (SABESP, 1976).

Em 1973, com o Planasa (Plano Nacional de Saneamento), todas as empresas foram reunidas em uma única, responsável pelo abastecimento de água e coleta de esgotos - a Sabesp (Companhia de Saneamento do Estado de São Paulo), que até hoje coordena esses serviços na Capital e em mais 672 municípios do Estado (YASSUDA, 1976).

A escolha da cidade de São Paulo foi baseada na complexidade do município paulistano, fonte inesgotável de debates e conclusões sociais, econômicas e técnicas para expansão de infraestruturas.

Como limitação espacial dentro da Cidade de São Paulo, usaremos a divisão em 96 distritos em conformidade com as informações disponibilizadas pela Companhia de Processamento de Dados do Município de São Paulo (PRODAM, 2006).

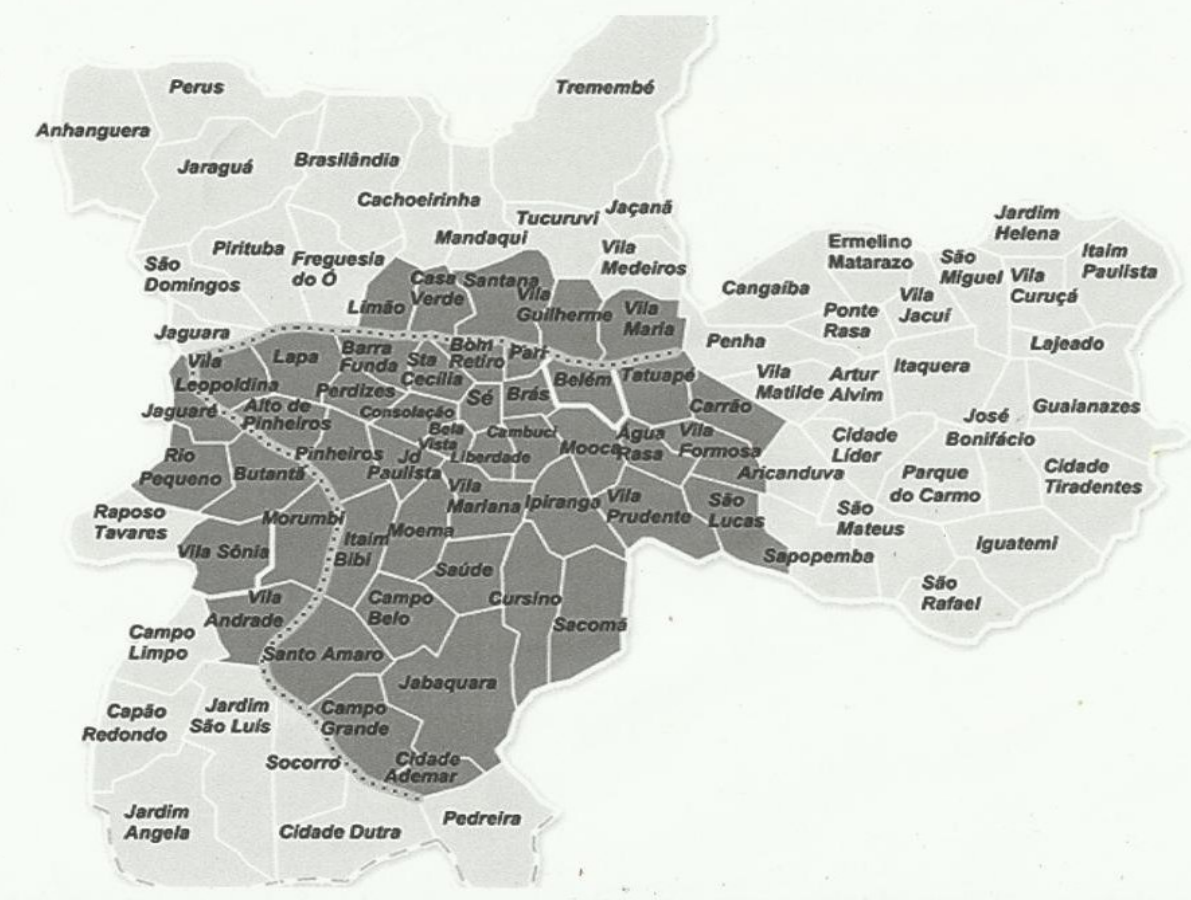

Figura 1-Os distritos ${ }^{1}$ da cidade de São Paulo abordados neste estudo. Figure 1-The districts of the city of São Paulo addressed in this study. Fonte: PRODAM, 2006.

\footnotetext{
${ }^{1}$ A área da figura 1 na cor mais escura representa a área intitulada "centro expandido", que é composta pelos distritos: Vila Leopoldina, Lapa, Barra Funda, Bom Retiro, Pari, Brás, Belém, Ipiranga, Vila Mariana, Pinheiros, Alto de Pinheiros, Perdizes, Santa Cecília, República, Sé, Consolação, Bela Vista, Liberdade, Cambuci, Jardim Paulista, partes de Moema, Itaim Bibi e Mooca (EMPLASA, 1993).
} 


\section{Evolução da distribuição territorial da rede de esgotos na capital paulista}

Em 1883, é criado o primeiro distrito de esgotos, no bairro da Luz, e implantada a usina de Ponte Pequena.

O texto a seguir reflete a situação da época:

“...assim como era comum o uso de chafarizes para água antes da implantação da Repartição de Águas e Esgotos da Capital, também o era o uso de poços negros para dejetos de despejos, cujo estado sanitário, entre 1887 e 1893, chegou a níveis insuportáveis... (ANDRADE, 1966, p269)”.

Como decorrência, no final da primeira década do século XX, grave epidemia de febre tifoide infestou a cidade.

$\mathrm{Na}$ década seguinte, começa "a renovação urbana, com a reforma de edifícios e a introdução do equipamento sanitário, com início na Vila Buarque, estendendo-se pela Luz e Bom Retiro" (ANDRADE, 1966, p.272).

Um dos agravantes para a deficiência do sistema nessa época, como é descrito a seguir por SCHALCH (1939, p.16), foi o fato de não existir um plano préestabelecido para a execução da rede:

...coletores atravessando quadras em diagonal, mudanças de grade sem poços de visita... E, em bairros centrais, como Santa Efigênia, Santa Cecilia, Luz, Sé, Liberdade Vila Buarque, funcionando sob sistema misto, com a rede de coleta de esgotos junto com a rede de captação de águas pluviais; com conseqüencias como o refluxo nas ruas pelos poços e no interior dos prédios pelos aparelhos sanitários, arrebentando canalizações...

Em 1911, lei proíbe o uso desse sistema. As redes novas começam a ser executadas pelo "Sistema se- parador absoluto", estudando a bacia antes do assentamento de coletores e nunca passando a rede por terrenos particulares (NOVAES, 1927).

No final da década de 30 , fez-se a revisão da chamada "rede velha", nos Distritos do Belém, Bela Vista, Vila Mariana, Mooca, Ipiranga, Consolação, Perdizes, Lapa, Brás, Jardim América, Santa Cecília, Liberdade, Santana, Cambuci, Santa Ifigênia, Bom Retiro, Sé e nos poucos pontos servidos da Penha e Butantã (WHITAKER, 1943).

Com o remanso ${ }^{2}$ estabelecido no Rio Tietê, para colaborar na alimentação da barragem de Parnaíba e com a inversão do Rio Pinheiros, já canalizado, para a alimentação da Usina de Cubatão, a Capital ficou cercada por águas poluídas de todos os lados: Tamanduateí, Tietê, Pinheiros e Billings (PMSP, 1958a).

Enfatizando essa situação, Plínio Whitaker, então Diretor do D.A.E, comenta em 1950: “O mau cheiro também vae invadindo os arrabaldes desta vertente, desde Butantan até Pinheiros, Jardim Europa, Jardim América e outros...” (WHITAKER, 1946, n.31, p.VIII).

Em 1952/53, foi elaborado projeto relativo ao tratamento e destino de águas de esgoto e resíduos industriais na região metropolitana de São Paulo, por contrato com uma firma norte-americana.

Este projeto deu origem à Estação de Tratamento de Vila Leopoldina. A seguir, no final dessa década, foram realizados estudos dividindo o Município em "distritos de esgoto", usando como limite a linha divisória de drenagem das bacias, levando em conta para o novo projeto, as características atuais e futuras dessas regiões com relação à ocupação por residências, comércio e indústrias.

Neste plano, foram criados para a cidade de São

\footnotetext{
${ }^{2}$ Mudança no regime de escoamento de um rio.
} 
Paulo, 22 áreas de controle. Este estudo também verificou as redes mistas ainda existentes, construídas no final do século XIX e elaborou um levantamento das ligações clandestinas, muito comuns em bairros, como por exemplo, o Cambuci e o Ipiranga (SABESP, 1976).

Outra questão foi enfatizada pelo estudo do solo da cidade, chegando à conclusão de que: "no solo argiloso e impermeável de São Paulo fossas sépticas ou fossas negras não são satisfatórias, a não ser que existam grandes áreas de infiltração". (AZEVEDO NETTO; NASDRUZ, 1958, n.31, p.41).

Aprovado por Portaria de janeiro de 1960, esse Plano instituiu a divisão da Região Metropolitana em 6 sistemas parciais e autônomos ${ }^{3}$ (DAEE, 1970):

- Vila Leopoldina, Casa Verde, Penha, Pinheiros, Santo Amaro e São Caetano.

Já na metade da década de 70, a rede era inexistente nas administrações Campo Limpo e Itaquera/Guaianazes; e muito precária em São Miguel Paulista, Pirituba/Perus, Butantã e Vila Prudente, além de ter vários pontos críticos na Freguesia do Ó, Penha, Santo Amaro, Vila Prudente, Santana e Mooca, ou seja, problemas em quase todo o Município.

Dez anos depois (SEMPLA, 1985), a situação era ainda bastante deficiente em áreas ao Norte da administração Freguesia do Ó, como no Jardim Peri-Peri, Jardim Santa Cruz, entre outros; na regional de Santo Amaro, em locais como Campo Grande, Parelheiros e Vila Joaniza; em Itaquera/Guaianazes, onde mais da metade da região era totalmente desprovida do serviço e em São Miguel - Ermelino Matarazzo e Campo Limpo, onde praticamente $100 \%$ da área não possuía rede, no geral, áreas em grande parte ocupadas por novos conjuntos habitacionais, que acabaram dificultando o prolongamento da rede em grandes distâncias e gerando alto custo de implantação.

Em 2000, conforme a Sabesp, 91\% da população é atendida, as regiões que apresentam ocupação urbana e não usufruem do serviço estão no extremo norte, beirando a região da Serra da Cantareira e em distritos como Anhanguera, e ao Sul, na região limite com as represas de Guarapiranga e Billings.

Conforme mapa da SABESP (2000) e PRODAM (2001), as regiões sul e leste têm praticamente todo o território servido.

A figura 2 e a tabela 1 compilam a expansão da cobertura do serviço no período em 1900-2000 e 18942000 , respectivamente.

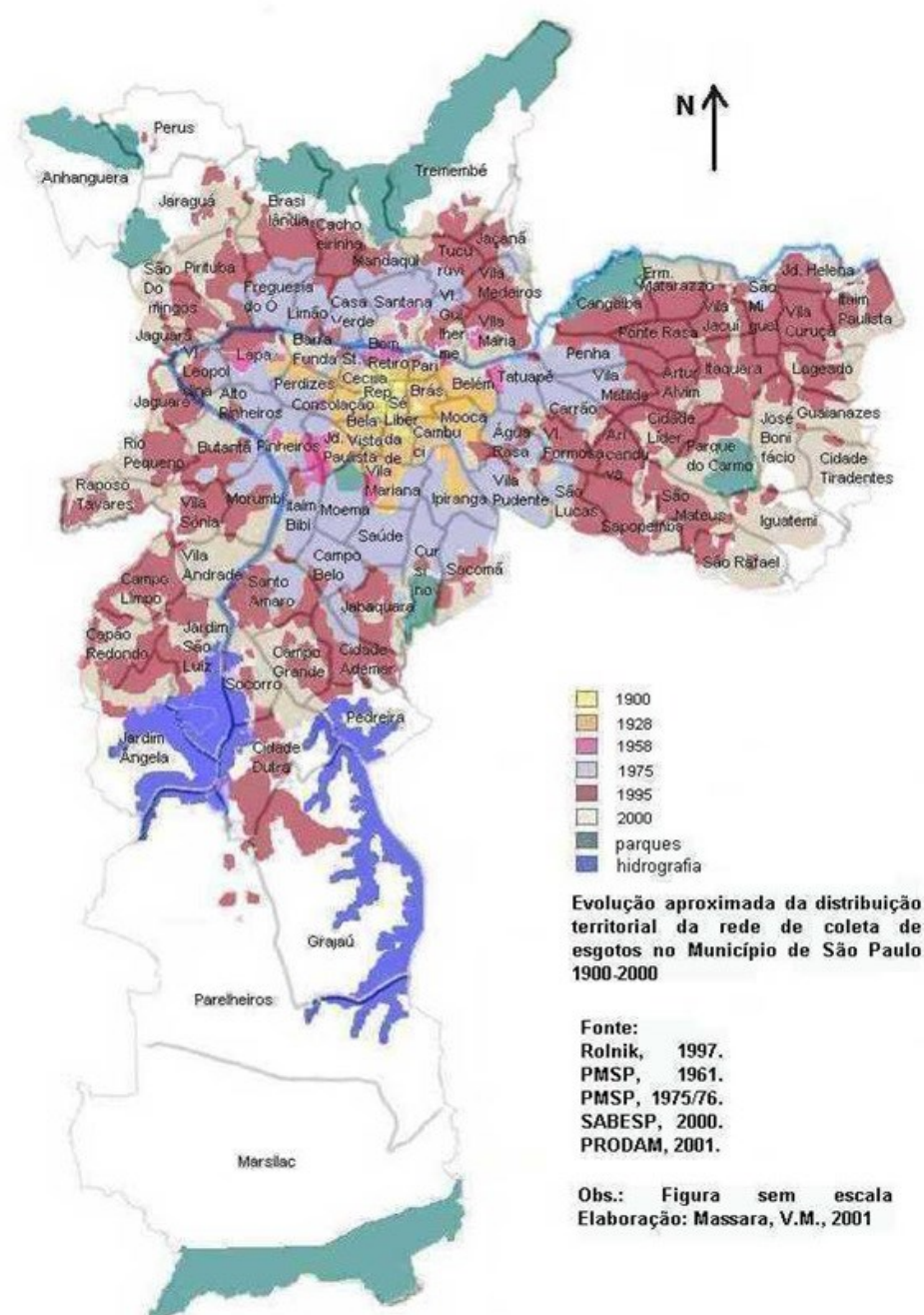

Figura 2-Evolução da distribuição territorial da rede de abastecimento de água no período 1900-2000.

Figure 2-Evolution of the territorial distribution of the sewage network in the period 1900-2000.

Fonte: MASSARA, 2002 com base em COGEP, 1975; PMSP, 1961; 1968b, SEMPLA, 1985; ROLNIK, 1997; SABESP, 1995; 2000; PRODAM, 2001, 2006. 


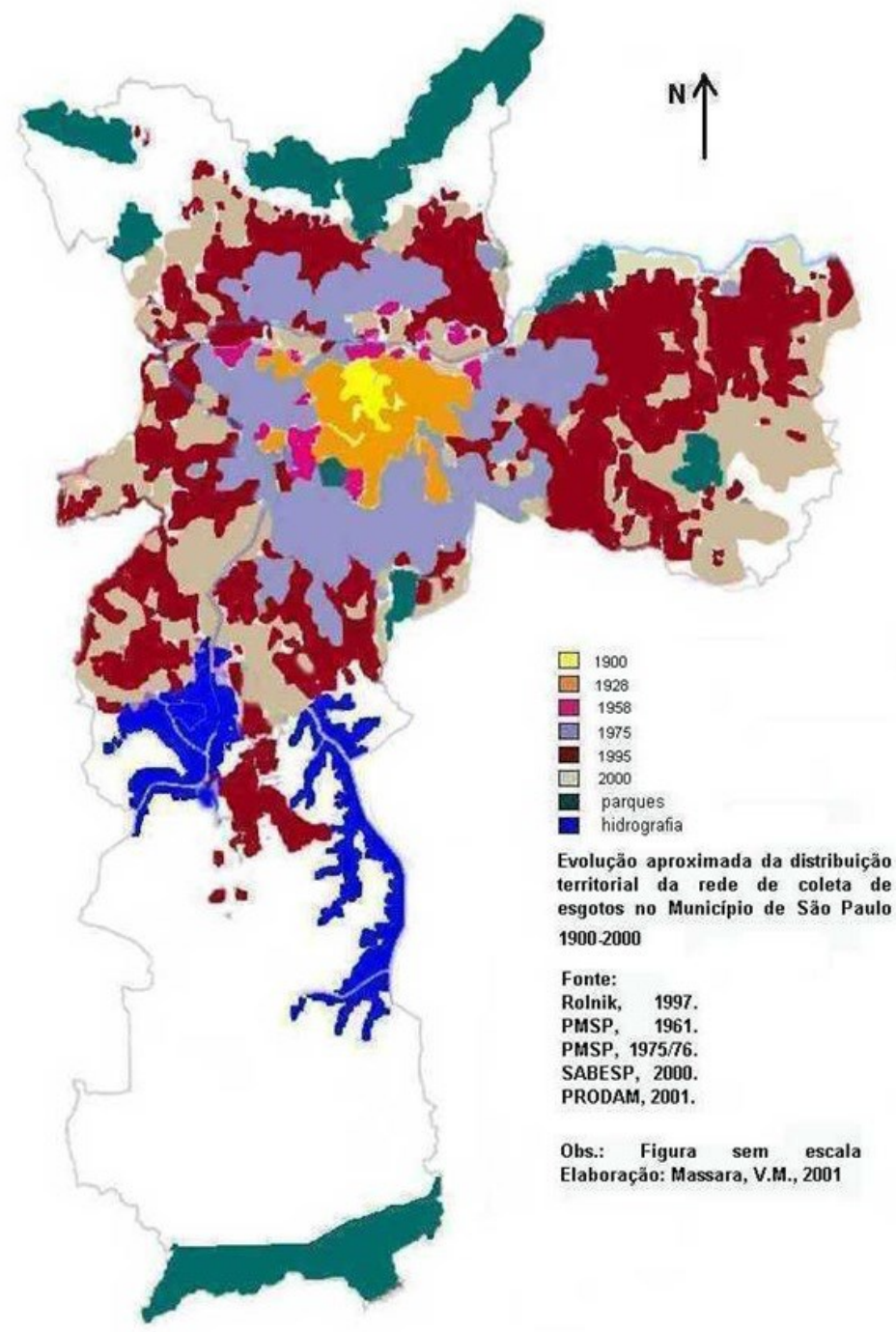

Figura 2-Evolução da distribuição territorial da rede de abastecimento de água no período 1900-2000.

Figure 2-Evolution of the territorial distribution of the sewage network in the period 1900-2000.

Fonte: MASSARA, 2002 com base em COGEP, 1975; PMSP, 1961; 1968b, SEMPLA, 1985; ROLNIK, 1997; SABESP, 1995; 2000; PRODAM, 2001, 2006.

\begin{tabular}{|c|c|c|c|c|c|}
\hline \multirow[b]{2}{*}{ Ano } & \multirow{2}{*}{$\begin{array}{c}\text { GERAL } \\
\text { população } \\
\text { total }\end{array}$} & \multicolumn{4}{|c|}{ COLETA DE ESGOTOS } \\
\hline & & $\begin{array}{l}\text { Número } \\
\text { Ligações à } \\
\text { Rede }\end{array}$ & \begin{tabular}{|c|} 
pop. \\
atendida \\
pela rede de
\end{tabular} & $\begin{array}{l}\% \text { pop. } \\
\text { A tendida }\end{array}$ & $\begin{array}{l}\text { extensão da } \\
\text { rede }\end{array}$ \\
\hline & (hab.) & & (hab.) & $(\%)$ & $(\mathrm{km})$ \\
\hline 1894 & 160.000 & 6.217 & 9.600 & 6 & 90 \\
\hline 1905 & 274.000 & 24.270 & \multicolumn{2}{|c|}{ não localizado } & 598 \\
\hline 1921 & 579.086 & 48.815 & \multicolumn{2}{|c|}{ não localizado } & 657 \\
\hline 1930 & 887.810 & 72.815 & \multicolumn{2}{|c|}{ não localizado } & 702 \\
\hline 1940 & 1.378 .539 & 106.485 & 496.274 & 36 & 755 \\
\hline 1945 & 1.696 .493 & 124.231 & 610.737 & 36 & 855 \\
\hline 1950 & 2.278 .000 & 140.267 & 751.740 & 33 & 932,5 \\
\hline 1955 & 2.916 .000 & 165.707 & 903.960 & 31 & 1.129 \\
\hline 1960 & 3.709 .274 & 194.196 & 1.112 .787 & 30 & 1.417 \\
\hline 1965 & 4.929 .674 & 253.479 & 1.577 .485 & 32 & 2.262 \\
\hline 1970 & 5.978 .977 & 349.960 & 2.379 .632 & 39,8 & $3.410,50$ \\
\hline 1975 & 7.710 .000 & 443.524 & 2.852 .700 & 37 & 3.932 \\
\hline 1980 & 8.493 .226 & 592.371 & 3.567 .155 & 42 & 6.589 \\
\hline 1985 & 8.864 .706 & 841.140 & 3.989 .118 & 45 & 7.302 \\
\hline 1990 & 9.646 .185 & 1.250 .282 & 6.270 .020 & 65 & 9.382 \\
\hline 1996 & 9.839 .436 & 1.564 .137 & 7.969 .943 & 81 & 12.892 \\
\hline 2000 & 10.406 .166 & 1.747 .963 & 9.469 .611 & 91 & 13.260 \\
\hline
\end{tabular}

Tabela 1-Resumo das informações numéricas sobre a rede de coleta de esgotos no período 1894-2000.

Table 1-Summary of numerical information on the sewage collection network in the period 1894-2000.

Fonte: Motta, 1911; Azevedo, A. 1958. Emplasa, 1993; Sabesp, 1976; Emplasa, 1977/ 98; IBGE, 1970, 2001; DAEE, 1970; Sempla, 1983; PRODAM, 2001; 2006. 


\section{Coletores, estações elevatórias e de tratamento 4}

A efetivação do tratamento dos esgotos depende das capacidades das estações, mas, principalmente, da eficiência do sistema, de maneira que a implantação de equipamentos auxiliares como coletores, e estações elevatórias acompanhe a evolução das capacidades de tratamento. Segue a lista de principais coletores e das estações elevatórias e de tratamento no período 1958-2000 (DAEE, 1970; PMSP, 1985; SABESP, 2017).

\section{Coletores}

Ênfase da construção no período de 1926, quando foram construídos os coletores da Penha e da Lapa e grande parte dos que servem as vertentes do Pinheiros.

Como parte do projeto Tietê, em 2000, foi concluído o emissário Pinheiros, evitando que 84 toneladas diárias de esgoto sejam lançados no Rio Pinheiros, sendo encaminhados para a Estação de Tratamento de Barueri.

\section{Elevatórias}

- Sistema ABC, Barueri e Suzano;

- Bom Retiro, Ponte Pequena, Avenida Presidente Wilson, Número I e II, Jaguaré, Bom Retiro, Vila Maria e Edu Chaves.

\section{Estações de tratamento}

1933: instalação experimental para tratamento de esgotos na Ponte Pequena

1937: estação experimental de tratamento de esgotos do Ipiranga (atual João Pedro de Jesus Netto) 1953: Vila Leopoldina década de 60: Pinheiros

\section{7: Barueri}

data não localizada: pequenas estações: Rio Grande da Serra e Dom Duarte

década 70: Mairiporã

década de 80: Suzano, Salesópolis.

1998: Sistema de Tratamento ABC, Parque Novo Mundo e São Miguel Paulista.

Em 1991, somente 20\% do esgoto coletado era m tratados; com grande parte dos despejos recebendo somente tratamento primário, ou seja, remoção parcial dos dejetos e lançamento diretamente nos rios e córregos. Em 1994, esse número subiu para 23\% e, em 2001, chegou a $64 \%$, devido ao da primeira fase do projeto Tietê (ANA, 2007).

Esse projeto implantado no período de 1992 a 1998, além da construção do coletor -tronco, emissário Pinheiros, ampliou a extensão das redes coletoras e suas ligações, concluiu a execução de três estações de tratamento: São Miguel, ABC e Parque Novo Mundo e reformulou a estação de Barueri, ampliando expressivamente sua capacidade (SEMPLA, 2000).

Com a segunda fase do projeto, o objetivo é aumentar as porcentagens de coleta e de tratamento, visando à elevação da qualidade de vida, ganhos para a saúde pública, a melhoria do meio ambiente e o aumento da disponibilidade de água potável, através de projetos para reuso da água.

Em 2000 (SABESP, 2017), havia em funcionamento quatro estações, sendo a mais importante, a Barueri, como mostram os dados numéricos da tabela 2 .

\footnotetext{
${ }^{4}$ Coletores são as tubulações responsáveis por conduzir o esgoto produzido em residências, comércio, prestação de serviços e indústrias aos interceptores que por sua vez, os conduzem até as estações de tratamento (SABESP, 2017).

Estações elevatórias de esgoto são definidas como aquelas usadas para elevar o esgoto a níveis em que possa prosseguir por ação da gravidade (SABESP, 2017).

Estações de tratamento de esgoto: locais onde o esgoto passa por processos químicos, voltando ao uso urbano para fins não-potáveis (SABESP, 2017).
} 


\begin{tabular}{|c|c|c|c|c|c|c|}
\hline Estação & 1958 & 1970 & 1980 & 1990 & 1993 & 2000 \\
\hline Pinheiros & 1,00 & 1,64 & 1,76 & 1,46 & 1,28 & \\
\hline Leopoldina & & & 1,75 & 0,04 & & \\
\hline Mairiporã & & & 0,13 & 0,03 & 0,02 & \\
\hline Suzano & & & & 0,33 & 0,49 & \\
\hline Salesópolis & & & & 0,01 & 0,01 & \\
\hline Barueri & & & & 3,33 & 4,29 & 9,5 \\
\hline São Miguel & & & & & & 1,5 \\
\hline ABC & & & & & & 3 \\
\hline Parque Novo Mundo & & & & & & 2,5 \\
\hline volume tratado total & 1,00 & 1,64 & 3,64 & 5,20 & 6,09 & 16,5 \\
\hline
\end{tabular}

Tabela 2-Evolução total do tratamento de esgotos da Grande São Paulo (m3/s) no período 1958-2000

Table 2-Total evolution of sewage treatment in Greater São Paulo (m3 / s) in the period $1958-2000$

Fonte: SANTIAGO, 1964; QUEIROZ, 1964; Emplasa, 1977/ 98.

\section{Breve enfoque das questões políticas, técnicas e sociais na implantação do saneamento básico na cidade de São Paulo}

O período entre o término do século XIX e as primeiras décadas do século XX, marcaram a introdução do urbanismo no país e na cidade de São Paulo. Com isso, os sistemas viários, o embelezamento e obras de "higienização", como a implantação do saneamento básico, ganharam importância, sempre associadas à interesses do mercado imobiliário.

$\mathrm{Na}$ capital paulista, a implantação das infraestruturas teve início no local mais antigo da cidade e que acaba constituindo o "centro". O sentido natural de sua evolução considera esse marco e a partir dele as facilidades técnicas de prolongamento das tubulações (como por exemplo a topografia), o custo de cada serviço conforme MASCARO (1979; 1992) e GARCIAS (1991), o que explica por que outras redes como a energia elétrica e o abastecimento de água chegam antes da rede coletora de esgotos e a concentração populacional gerada pelo próprio histórico de criação e desenvolvimento dos bairros ao redor do ponto inicial.

Neste estudo, constata-se (como ilustra a figura sobre a evolução da distribuição territorial da rede coletora de esgotos) que a instalação dos serviços começou na área central da cidade, estendendo-se de forma apro- ximadamente concêntrica ao redor desse primeiro centro, abrangendo a região atualmente denominada por centro expandido.

Após a década de 70, a implantação vai-se consolidando na região periférica da cidade, principalmente nas zonas sul e leste, as menos atendidas até então.

A importância da infraestrutura é difícil de ser mensurada por muitas vezes estar ligada a fatores de caráter subjetivo, como o que cada um entende por qualidade de vida conforme sua realidade. A necessidade do serviço muda conforme o período ou região de estudo, assim, por exemplo, a importância dada ao saneamento básico no centro histórico data de início do século, já para os distritos ao redor desse primeiro núcleo se concentra entre as décadas de 20 e 50, enquanto que, para os extremos leste e sul, essa questão tomou vulto a partir da década de 60 (esta observação está diretamente associada as diferentes fases de incremento demográfico de cada região).

Porém, é notório que a introdução das infraestruturas em uma determinada região funcione como uma "vantagem competitiva" na atração de usos, resultando na sofisticação dos usos já instalados.

Como enfatiza Toledo Silva (1995, p.19): “a infraestrutura é implantada principalmente em função das necessidades da atividade econômica e do consumo, e não necessariamente em benefício das comunidades residentes por onde ela passa".

As áreas de maior expansão do uso terciário são aquelas que primeiro recebem os serviços. $\mathrm{O}$ maior consumidor entre os tipos de uso do solo é o residencial, seguido pela utilização comercial e de prestação de serviços e, em último lugar, pelo uso industrial (VILLAÇA, 1978).

Por outro lado, a constante e desordenada ocupação das áreas leste e sul da cidade acabaram por difi- 
cultar que as redes de infraestrutura acompanhassem esse processo, porém, como afirma o relatório da Secretaria Municipal de Planejamento Urbano, "sendo as áreas centrais as que possuem melhor infra-estrutura no município, pode-se concluir que a pressão exercida em seu nome, por investimentos públicos e privados, tende a criar um círculo vicioso de concentração de renda e riqueza no território urbano" (SEMPLA, 2000, v. 3 p.42), e com isso, maior acesso às redes, entre elas o saneamento básico.

Indiretamente, constata-se que o agrupamento de formações de uso do solo e consequente implantação das infraestruturas. Essa relação é baseada no conjunto de características da cidade a começar pela implantação de seu núcleo inicial e consolidação do "centro" culminando com o direcionamento de investimentos visando ao setor imobiliário e à sua valorização no setor oeste da cidade.

De forma resumida, o esquema ilustrado a seguir (figura 3) inter-relaciona todos os aspectos que determinam a implantação das redes em regiões centrais e periféricas.

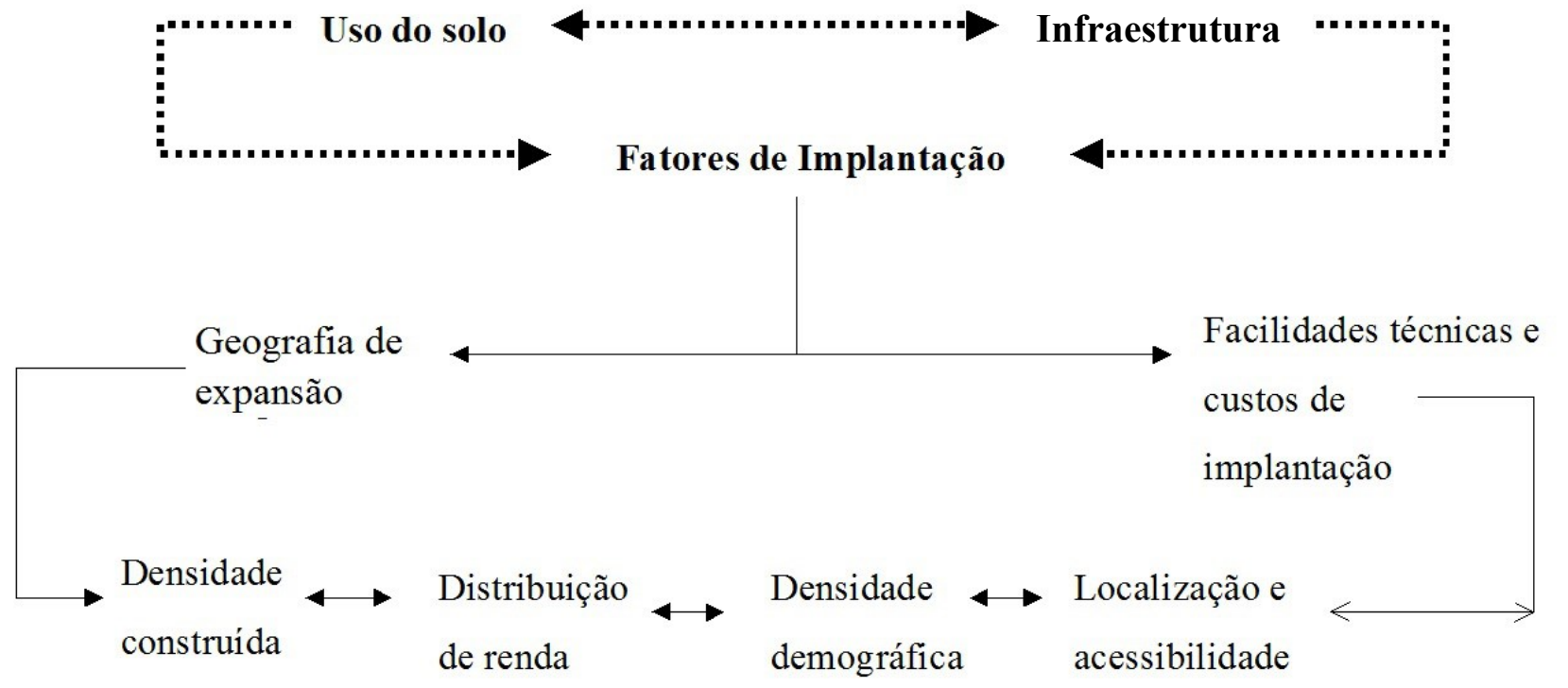

Figura 3. Fatores intervenientes na seleção de locais prioritários para a implantação de infraestruturas. Figure 3. Intervening factors in the selection of priority places for the implementation of infrastructures. Fonte: elaboração do autor.

diferentes usos do solo em uma mesma região atrai maior atenção na implantação dos serviços. Os usos comercial e residencial de alto padrão foram os principais responsáveis pela rapidez na instalação das infraestruturas (VETTER; MASSENA, 1975).

Também o conceito de potencial de adensamento incita que áreas já urbanizadas e consolidadas recebam melhorias constantes, aproveitando a ocupação existente, visando a diminuir custos de expansão de dutos e instalações (GUALDA, 1992 e MIGLIORINI, 1997).

Através desta breve análise, fica explícito que existe uma relação de maior peso envolvendo as trans-
Sabemos que é superficial dizer que a localização e concentração de renda são preponderantes na determinação dos locais que receberão os serviços e na rapidez com os quais serão instalados. Mas a influência dos interesses do mercado imobiliário sempre deve ser considerada como ponto-chave na instalação das infraestruturas (ROLNIK, 1997).

A gama de fatores que intervêm na seleção de áreas a servir, consideradas questões técnicas, econômicas e políticas, nem sempre tendo como prioridade as necessidades de cunho social. Este trabalho não tem a intenção de se aprofundar na relação entre esses fatores.

Entende-se que é difícil acompanhar a expansão 
populacional, ao mesmo tempo que essa população exige a presença da infraestrutura como um requisito mínimo de qualidade de vida. A complexidade na tomada de decisão sobre a implantação e expansão das redes de infraestrutura de cunho público, em especial o saneamento básico, continuará a ser tema relevante e de constantes estudos na cidade e no país.

\section{Breve enfoque das questões urbanísticas em paralelo à implantação do sanea- mento básico na cidade de São Paulo}

Cabe destacar os principais fatores de caráter urbanístico e que concorreram para a expansão da cidade e para as diferenças no atendimento entre as regiões central e periférica.

A implantação da primeira ferrovia em solo paulista (São Paulo Railway), na segunda metade do século XIX, foi o impulso necessário para a alteração da paisagem do planalto, com o fortalecimento da centralidade da cidade de São Paulo que, a partir do início da operação da estrada, pôde abrigar as famílias dos cafeicultores e, além dos negócios do café, ver nascerem fábricas e indústrias que se tornaram importante marca da metrópole paulistana por todo o século XX (ZMITROWICZ, 1984).

Por causa das indústrias que se instalavam ao longo da ferrovia, as proximidades das estações exerciam um atrativo para esses trabalhadores que buscavam áreas de preço acessível para aquisição de terrenos, casas ou aluguel de moradias, enquanto podiam beneficiar -se de um meio de transporte fácil e próximo para se locomoverem de casa para o trabalho e vice-versa. Por isso, vários trechos lindeiros a ferrovia foram ocupados e desenvolveram-se, formando bairros residenciais e autênticos "subúrbios dormitórios". (METRO, 2012, p.23).

Outro fator de expansão da cidade foi a instituição da "limpeza social" nos cortiços, habitações precá- rias, muitas em porões insalubres localizadas na área central da cidade.

Conforme afirma Passarelli (2008, p.91):

\begin{abstract}
"Na primeira década do século $X X$, os boatos de que o centro passaria por uma grande e custosa reforma serviram de justificativa para alavancar os preços dos aluguéis, movimentando um verdadeiro êxodo do centro para os bairros populares distantes que continua no pós1930, com o conceito de: "[..] facilitar o acesso à casa própria [...] viabilizando a ocupação da chamada zona rural, ou perférica da cidade " (BONDUKI, 1998, p.89).
\end{abstract}

Também segundo Saraiva (p. 25):

"Foi a promulgação da Lei do Inquilinato em 1942, que congelou os aluguéis, reeditada até 1964, que acelerou o processo em curso de expansão periférica e a difusão da idéia da casa própria, uma vez que desestimulou a produção de moradias para aluguel e ocasionou indiretamente grande número de despejos".

Assim, na década de 1960, a região anelar mais periférica da cidade, compreendendo a Zona Leste, Zona Noroeste e sul, viriam crescer cerca de $13 \%$ ao ano, cifra muito mais alta que a do município no período (4,6\% AA) (JANNUZZI, 2004).

Fatores como expansão das vias e dos meios de transporte, também induziram a expansão periférica. Durante os anos 30, foi organizado pelo Engenheiro Prestes Maia o Plano de Avenidas. Foi um dos responsáveis pela expansão da cidade e, consequentemente, pela sua periferização combinando as novas possibilidades de transporte coletivo através dos bondes, propostas no Plano de Remodelação do Sistema de Transportes Públicos da Light.

A expansão da rede de transporte coletivo por intermédio dos ônibus foi o principal instrumento dessa remodelação.

Nos anos 70, com a criação do Metrô, a periferia passou definitivamente a constituir imensas áreas, as 
denominadas "cidades-dormitório" para população de baixa renda, com déficits em serviços e infraestruturas. Bomtempi (1970, p.173) resume a situação: “a distância física é significativa para as relações humanas quando pode ser interpretada em termos de distância social".

\section{Segundo Cestaro:}

"apesar da visão de conjunto, é nítido que as ações empreendidas pela municipalidade no campo do urbanismo restringiam-se ao perimetro central da cidade, pois até os anos 1950 as administrações não demonstravam preocupação pelas áreas distantes e os novos bairros que surgiam na periferia da cidade [...]" $(2013$, p.10)

Essa expansão perdurou pelas décadas seguintes, motivada em grande parte pelo grande contingente de migrantes que se instalou predominantemente ao leste e ao sul da capital.

Segundo Torres (2004, p.2): “A ocupação das áreas peri-urbanas por parte de uma população predominantemente de baixa renda ainda é um dos elementos fundamentais da estruturação da metrópole paulistana no início do século XXI.”

\section{Conclusões}

A determinação dos locais a serem atendidos pelas redes leva em conta vários critérios. Partindo da área mais antiga e, consequentemente, com maior população, a demanda é o primeiro critério considerado.

Considerando a localização e a possibilidade de acesso como importantes agentes de transformação dos usos, levando em conta o tempo e custos de deslocamentos para chegar a áreas com concentração de empregos, o "centro" tem papel relevante na atração dos serviços.

Estar no "centro", além de propiciar o fácil acesso a qualquer região da cidade e permitir a utilização de serviços e equipamentos sofisticados, determina, na maior parte das vezes, o status social.
Conclui-se a priori que a escolha por locais próximos ao centro comercial, com ruas pavimentadas e servidas por vários tipos de transportes, marca o processo de valorização imobiliária, tendo o vetor oeste da cidade a prioridade na instalação das redes.

Formando um círculo vicioso, a consolidação do centro e consequente atração de serviços urbanos e diferentes usos concentra de forma geral nas suas proximidades, a população de maior poder aquisitivo e acaba por "expulsar" os mais pobres para a periferia longínqua e desprovida de equipamentos.

Em oposição às questões indicadas anteriormente, que induzem a conclusão de que o centro foi beneficiado em detrimento da periferia, deve-se mencionar que um fator decisivo para a qualidade dos serviços em regiões periféricas é a sua expansão desordenada e muitas vezes clandestina.

A localização e concentração de renda não são necessariamente preponderantes na determinação dos locais que receberão os serviços e na rapidez com os quais serão instalados.

As dificuldades construtivas e a própria expansão rápida e desordenada da cidade impossibilitam o fluxo direto de implantação e criam problemas maiores como o constante investimento em áreas com déficits e o abandono de outras questões (como a proteção aos mananciais).

Conclui-se que o processo de implantação das redes é dependente de diversos fatores que geram um círculo complexo de interesses e real necessidade dos serviços. Outro ponto relevante reside no fato de que, ao mesmo tempo em que se faz necessário estender os serviços por todo o Município, também é necessária a manutenção da rede antiga.

Equilibrar a expansão da cidade com o seu desenvolvimento continuará a ser um desafio neste novo século. 


\section{Siglas}

ANA: Agência Nacional de Águas

COGEP: Coordenadoria Geral de Planejamento

DAE: Departamento de Águas e Esgotos

DAEE: Departamento de águas e Energia Elétrica

EMPLASA: Empresa Metropolitana de Planejamento

IBGE: Instituto Brasileiro de Geografia e Estatística

PMSP: Prefeitura do Município de São Paulo

PRODAM: Companhia de Processamento de Dados do Município de São Paulo

SABESP: Companhia de Saneamento Básico do Estado de São Paulo

SEMPLA: Secretaria Municipal de Planejamento

\section{Referências}

ANDRADE, Francisco de Paula Dias de. Subsídios para o estudo da influência da legislação na ordenação e na arquitetura das cidades brasileiras. São Paulo, Tese (livre docência), Escola Politécnica da Universidade de São Paulo, 1966, pg. 264/272.

AZEVEDO, Aroldo de. (org). A Cidade de São Paulo. São Paulo, Associação dos Geógrafos brasileiros. Rio de Janeiro: Companhia Editora Nacional, Vol II-IV 1958.

AZEVEDO NETTO, José M.; NADRUZ, Nassim. A estação de tratamento de esgotos de Vila Leopoldina. Revista do DAE. São Paulo, Repartição de Águas e Esgoto de São Paulo - Secretaria de Viação e Obras Públicas. Número 31, Julho, 1958, p.V-XVI.

AZEVEDO NETTO, José M. Cronologia do abastecimento de água até 1970. Revista do DAE. São Paulo, Repartição de Águas e Esgoto de São Paulo - Secretaria de Viação e Obras Públicas. Número 137, Julho, 1984.

AGÊNCIA NACIONAL DE ÁGUAS - ANA. A História do Uso da Água no Brasil. Do Descobrimento ao Século $X X$. Brasília, 2007.

BOMTEMPI, Sylvio. O bairro de São Miguel Paulista. São Paulo, Departamento de cultura da Secretaria de Educação e Cultura. Série História dos Bairros, v. VII, 1970.

BONDUKI, Nabil. Origens da habitação social no Brasil: Arquitetura moderna, Lei do Inquilinato e difusão da casa própria. São Paulo: Estação Liberdade, 1998.

CESTARO, Lucas Ricardo. A SAGAMCS e o estudo da aglomeração paulistana. Revista Urbana, v.5, n. 6, mar.2013. p.1-16.

COMPANHIA DE SANEAMENTO BÁSICO DO ESTADO DE SÃO PAULO - SABESP. Metas para o Abastecimento de Água da Região Metropolitana 1975-78. São Paulo, 1976.

. Mapa da Rede de Abastecimento de Água. São Paulo, 1995.

. Mapa da Rede de Esgotos. São Paulo, 2000.

. Sitio web: Histórico. Disponível em: <http://www.sabesp.com.br>. Acesso em: 15.ago.2017.

COORDENADORIA GERAL DE PLANEJAMENTO- GOGEP. Administrações Regionais, 16 v. São Paulo, 1975.

COMPANHIA DE PROCESSAMENTO DE DADOS DO MUNICÍPIO DE SÃO PAULO - PRODAM. Atlas Ambiental. São Paulo, 2001.

Informações urbanas (2006). Disponível em: <http://www.prodam.sp.gov.br>. Acesso em: 12.mai.2017.

DEPARTAMENTO DE ÁGUAS E ENERGIA ELÉTRICA- DAEE. Distribuição de água e coleta de esgotos em São Paulo: afastamento e disposição de esgotos na área metropolitana. São Paulo, 1970.

EMPRESA METROPOLITANA DE PLANEJAMENTO - EMPLASA. Sumário de Dados da Grande São Paulo.

São Paulo, 1977/1998. 
. Reconstituição da memória estatística da Grande São Paulo. São Paulo, 1993.

GARCIAS, Carlos Mello. Indicadores de qualidade dos serviços de infra-estrutura de saneamento. Tese (Doutorado), Escola Politécnica da Universidade de São Paulo, 1991.

INSTITUTO BRASILEIRO DE GEOGRAFIA E ESTATÍSTICA - IBGE. Censo Predial. Região Sudeste. São Paulo, Ibge, 1970.

. Censo 2000. Indicadores socioeconômicos. São Paulo, 2001.

JANUZZI, Paulo de Martini. São Paulo, século XXI: a maior metrópole das Américas. Ciência e Cultura, v.56 n.2, 2004. p.1-21.

MASCARÓ, Juan Luis. Custos de Infra-Estrutura: um ponto de partida para o desenho econômico urbano. São Paulo, Tese (doutorado), Faculdade de Arquitetura e Urbanismo da Universidade de São Paulo, 1979.

. Desenho Urbano e custos de urbanização. Brasília, Ministério da Habitação, Urbanismo e Meio Ambiente,

1992.

MASSARA, Vanessa Meloni. O perfil da infra-estrutura no Município de São Paulo e sua relação com as transformações de uso do solo: o centro expandido e a região de São Miguel Paulista. São Paulo: Escola Politécnica da Universidade de São Paulo, 2002.

MIGLIORINI, Vera Lúcia Blat. Os padrões de desempenho do uso e ocupação do solo na previsão e controle de adensamento de áreas intra-urbanas Tese (Doutorado), Escola Politécnica da Universidade de São Paulo, 1997.

MOTTA, Arthur. Estudos Preliminares para o reforço do abastecimento d'água na cidade de São Paulo. São Paulo, S.N., 1911.

NOVAES, Henrique de. Relatório da Comissão de Obras novas do abastecimento de água da Capital. São Paulo, TYP. Brazil, 1927.

PASSARELLI, Silvia Helena Passarelli. De Santos a Jundiaí: a primeira ferrovia paulista (Parte 1). Historia ehistória. UNICAMP, dez, 2008.s/p.

PREFEITURA DO MUNICÍPIO DE SÃO PAULO - PMSP. Plano Urbanístico Básico. Consórcio Asplan, Daily, Montreal, Wilbur Smith, voume.2 -Desenvolvimento Urbano, 1968a.

. Plano Urbanístico Básico. Consórcio Asplan, Daily, Montreal, Wilbur Smith, volume.5 - Infra-Estrutura, $1968 b$.

. Planos para cinco regiões administrativas do Município de São Paulo. PMSP, 1985.

Relatório da Gestão Ademar de Barros 1958 -1961. PMSP, 1961.

QUEIROZ, Victor Oscar de Seixas. Abastecimento de Água na Cidade de São Paulo. Revista do DAE. São Paulo, Repartição de Águas e Esgoto de São Paulo - Secretaria de Viação e Obras Públicas. Número 52, pgs. 29/48, Março, 1964.

ROLNIK, Raquel. A Cidade e a Lei: legislação, política urbana e territórios na Cidade de São Paulo. São Paulo: Studio Nobel Fapesp, 1997.

SANTIAGO, Francisco, A. Quadro dos reservatórios que abastecem a cidade de São Paulo. Revista do DAE. São Paulo, Repartição de Águas e Esgoto de São Paulo - Secretaria de Viação e Obras Públicas. Número 52, pg. 54/55, Março, 1964.

SÃO PAULO (ESTADO) METRO. Gestão Ambiental EIA-RIMA - Estudo de Impacto Ambiental e Relatório de Impacto Ambiental LINHA 18 - BRONZE. São Paulo: Metro, 2012.

SCHALCH, José Emiliano. Revisão das Redes de Esgoto da Cidade de São Paulo. Boletim Técnico da RAE. São Paulo, Repartição de Águas e Esgoto de São Paulo - Secretaria de Viação e Obras Públicas. Número 8, pg. 15/19, Dezembro, 1939.

SECRETARIA MUNICIPAL DE PLANEJAMENTO - SEMPLA. Diagnóstico regionalizado do município de São Paulo. São Paulo, 1983.

Plano do Município de São Paulo 1985-2000. São Paulo, 1985. 
. Perfil socioeconômico do Município de São Paulo. São Paulo, 2000.

. Evolução do Uso do Solo nos anos 90. São Paulo, PMSP, 2000.

TELlES, Pedro Carlos da Silva. História da Engenharia no Brasil - século XX. Rio de Janeiro, Clube de Engenharia, vol. 2, 1984.

TOLEDO, Ricardo Toledo. Oferta de infra-estrutura e revitalização do centro: aspectos da gestão e do controle social. São Paulo: Associação Viva o Centro, 1995. p.19.

TORRES, Haroldo da Gama. Fronteira Paulistana. In: XIV Encontro Nacional de Estudos Populacionais, 2004. p.1-12.

VETTER, David Michael. Espaço, valor da terra e equidade dos investimentos em infraestrutura urbana:uma análise do Município do Rio de Janeiro. Rio de Janeiro, Departamento de Estatística e Indicadores Sociais, 1975.

VILLAÇA, Flávio José Magalhães. Uso do Solo. São Paulo, Faculdade de Arquitetura e Urbanismo da Universidade de São Paulo, 1978.

WHITAKER, Plínio Penteado. Abastecimento de água na Cidade de São Paulo. Sua Solução. Boletim Técnico da RAE. São Paulo, Repartição de Águas e Esgoto de São Paulo - Secretaria de Viação e Obras Públicas. Número 17 , pg. 3/22, Novembro, 1946.

. Relatório referente ao ano de 1942. Boletim Técnico da RAE. São Paulo, Repartição de Águas e Esgoto de São Paulo - Secretaria de Viação e Obras Públicas. Número 12, pg. 24/35, Março, 1943.

YASSUDA, Eduardo Riomey. Projeto de Abastecimento de água para a região metropolitana de São Paulo 1975 78. Revista do DAE. São Paulo, Repartição de Águas e Esgoto de São Paulo - Secretaria de Viação e Obras Públicas. Número 106, pg. 24/27, 1976.

ZMITROWICZ, Witold. Obras públicas de engenharia e sua função na estruturação da cidade de São Paulo. São Paulo, Tese (doutorado), Escola Politécnica da Universidade de São Paulo, 1984.

Submissão: $27 / 09 / 2017$ Aceite: 18/01/2017 